\title{
Private Versus Public Systems for Industrial Accidents and Invalidity Insurance: - The German Solution -
}

\author{
by Günther Sokoll*
}

\section{Introduction}

Germany has a dual insurance regime. Insurance cover for accidents at work and occupational diseases of employees is provided by the statutory accident insurance institutions. The principal areas of private accident insurance are the domestic sphere as well as leisure and transportation. There is no correlation between private accident insurance and the benefits provided by statutory accident insurance institutions; it is more a case of both following the precept of working together in a complementary way.

Public insurance is arranged in a comprehensive manner. This is expressed by the law's stated aim of preventing work accidents "by all appropriate means", and of restoring the health and work capacity of the insured persons "by all appropriate means" following the occurrence of work accidents and occupational diseases and to provide them and their dependants with financial compensation. There is clearly no place here for private accident insurance to operate in a compensatory way.

German industrial accident insurance is part of the social legislation introduced by Bismarck. It has continued to develop quantitatively and qualitatively over 110 years, both in terms of the scope of insurance cover and the range of benefits. Over the past months during a phase of clear political willingness to reorganize the welfare state - industrial accident insurance has been carefully examined by the legislature and its fundamental structures have been comprehensively acknowledged. There were no calls during the parliamentary debate for the privatization of industrial accident insurance, for example.

The present situation can be summarised thus: in Germany private and statutory accident insurance providers operate in peaceful existence. Competition between statutory and private insurers is limited to the case of the voluntary insurance effected by companies.

In their capacity as statutory accident insurers, the statutory accident insurance institutions perceive their role in terms of a service linking businesses and the public administration. This finds its visible expression in the self-governing responsibilities of employers and insured persons for the administration of the insurance provisions.

\footnotetext{
* Hauptverband der gewerblichen Berufsgenossenschaften e.V. (Central Organisation of the Statutory Accident Prevention and Insurance Institutions in Industry).
} 


\section{Group of persons covered}

In private accident insurance the insurance relationship is created by contract. The insurance cover provided by statutory accident insurance is regulated by legislation.

The law provides for compulsory accident insurance to encompass three groups of persons:

- All persons whose insurance cover is directly linked to their employment. Those only employed to a limited extent are also insured; the extent of the work accident risk is not relevant.

- Trainees during work-related training programmes in the workplace, training workshops, training courses and similar activities, children at day-time institutions, pupils and students in further education.

- The third group of persons is very heterogeneous. It comprises, inter alia, disabled persons in workshops, persons undergoing rehabilitation, persons carrying out certain honorary duties, life savers, blood donors, carers, witnesses.

Persons running a business and their spouses working in the undertaking can voluntarily insure themselves with the statutory accident insurance sytem, as can persons who regularly act in a similar capacity in joint-stock companies and companies with unlimited liability.

Persons are not insured if the accident provisions relating to State employees or similar arrangements apply to them. Self-employed doctors, dentists, veterinary surgeons, paramedical practitioners and chemists are also not covered.

Housewives are not covered by the statutory accident insurance; there has been no legislative response to repeated demands to this effect. Pensioners no longer have a work status and are therefore automatically not covered by the statutory insurance.

Employees are also insured even if their employer has not paid the contribution to the accident insurance provider. This is not the case for private accident insurance where the contract is the basis of the cover and the performance of the contract is dependent on payment of the premium.

In contrast to private insurance, there is no such thing as an uninsurable person as far as the statutory accident insurance is concerned. Here, physically and mentally disabled persons, as well as those requiring care, are covered as long as they are involved in an insured activity. There are no age limitations, as can be the case when first taking out a private insurance policy.

The statutes can also allow the accident insurance providers to extend the obligation to insure those firms who are not already insured in accordance with the legal requirements. About half of the statutory accident insurance institutions have made use of this.

\subsection{Liability and accident insurance}

The liability of factory owners was increased by the introduction of the German Liability Law of 1871. At the same time this had the effect of strongly boosting the development of private insurance. Numerous newly founded private liability and accident insurance companies offered liability insurance to firms in conjunction with group accident insurance for the workforce. When liability of the firms was replaced by public legal liability of the statutory accident insurance institutions in 1884, it became largely unnecessary to take out appropriate private liability policies. Initially, this public legal accident insurance only related to businesses; it was only in 1942 that the law was changed to a comprehensive insurance of individuals. 


\section{Insured risks}

In statutory accident insurance, the risks of industrial accident, occupational diseases, and accidents during journeys to and from work are insured:

3.1. The definition of what constitutes an accident is virtually identical in private and statutory accident insurance: accidents are temporally limited incidents, externally affecting the body, causing damage to health or death.

However, differences do exist in the evaluation of the causality that must exist between the incident and the damage to health. Statutory accident insurance places more stringent demands on the qualification criteria of the accident. This is a consequence of the premise that private accident insurance covers all accidents.

In private insurance, the injury will be recognised where there is adequate causality, i.e. the incident causing injury need not be the sole cause of the damage to health. By contrast a simple cause is not sufficient as far as statutory accident insurance is concerned; a significant contribution of partial causes is needed. Social security insurance practice requires the stricter formulation of significant causality in order to limit its liability risk, as otherwise liability would also arise for factors unrelated to accidents such as illnesses or own fault. Conversely private insurance law permits a reduction of benefits when an accident also involves factors not related to the accident.

The time aspect of an "accident" is more generously interpreted by the statutory accident insurance. In statutory accident insurance, an incident is considered to be sudden and temporally limited if it occurs in a relatively short time period, at most, during a working shift. In private accident insurance, an incident lasting for two and a half hours would no longer be deemed "sudden". In statutory accident insurance, damage to prosthesis is treated in the same manner as injury to the body.

Unlike statutory insurance, private accident insurance excludes certain risks, such a accidents resulting from diminished concentration caused by the consumption of alcohol. On the other hand, statutory accident insurance also withdraws cover in the event of drunkenness and the use of drugs or medication, if these were the sole cause of the accident in law. However, the insured person remains covered if the consumption of alcohol only leads to a reduction in ability and he is still fundamentally capable of working effectively.

3.2. The statutory insurance institutions also insure the following activities:

- travelling directly to and from the place of the insured work activity,

- a deviation from that journey in order, in defined circumstances, to place the children of insured persons in the care of third parties,

- deviations from that journey for vehicle sharing purposes with other employees or insured persons.

There are significant interfaces between insurance for accidents during work-related journeys and private insurance because, both in practice and in legal judgements, the question of detours and deviations inevitably generates much argument.

3.3. The illnesses insured by the statutory insurance institutions as occupational diseases are those included in a special federal government register that is regularly updated. The registered diseases are those that, according to the findings of medical science, are caused by 
particular factors to which particular groups of people have a considerably higher exposure, due to their insured working activities, than the rest of the population. If an occupational disease is recognised by new medical findings as corresponding to this definition, the statutory accident insurers must provide compensation for such an disease even if it arose prior to inclusion in the register.

Compensation for occupational diseases is very problematic for statutory accident insurance; difficult areas include the many different factors contributing to the development of occupational diseases, proof of exposure and danger to health where there are long periods of latency in the development of occupational diseases and the exclusion of natural deterioration and general illnesses.

Occupational diseases, as well as poisoning, infectious illnesses, and damage to health by radiation are not covered by private accident insurance.

\section{Range of benefits}

4.1. The benefits provided by private insurance are determined by the policy and in compulsory insurance by the law. In both cases payment of benefits is conditional upon death or invalidity, i.e. loss or reduction of earning capacity. The definition of "invalidity" as the "permanent impairment of the ability to work" that is used in private insurance is not identical to the definitions used by statutory accident insurance in respect to loss or reduction of earning capacity. The ability to work is solely determined on the basis of medical findings. The expression "earning capacity" not only refers to the impairment of physical and mental abilities caused by the accident, but also the resultant reduction in working opportunities across the whole area of earning potential.

4.2. Private insurance typically only pays monetary benefits in the form of a capital sum that can be converted into an annuity but does not provide payments in kind nor risk prevention measures. In the event of death or invalidity, private accident insurance always pays a capital sum corresponding to the agreed sum insured. Statutory accident insurance differs in that benefits are always provided in pension form - for dependants or for injured persons - the upper limit of which is only restricted by the maximum annual income amount determined by statute or by the regulations of the accident insurance provider. In the event of death, the statutory accident insurance provider is released from the obligation of paying any benefits (with the exception of burial costs) if there are no dependants entitled to them.

4.3. The benefits of the private insurers are also subject to a limit: compensation for death is only payable if occurring within one year of the date of the accident. With invalidity compensation, the permanent impairment of the ability to work must also arise within the first year and be medically diagnosed and validated within the first 15 months. No such restrictions apply in the statutory accident insurance.

The payment of any allowance for the duration of medical treatment will be limited to a maximum of one year from the date of the accident. A hospital allowance will be payable for a maximum of two years and a convalescence allowance up to the 100th day following the hospital stay. Medical expenses incurred within the first year after the accident for the treatment of the injuries resulting from the accident are reimbursed up to the sum insured. 
4.4. A side effect of the benefits of private insurance is a loss compensation function, although this is not the actual intention. From the perspective of statutory accident insurance it is purely a monetary benefit system where the insurance benefits paid and the actual accident injuries are only related to the extent of the sums insured agreed in the policy.

Statutory accident insurance has a wide range of benefits. The amount of the incomeoriented monetary benefits is only indirectly related to the contributions in so far as they reflect annual earnings. The rehabilitation benefits and prevention measures are based on what is required. The legislative purpose is to restore the health and work capacity of the insured persons by all appropriate means following the occurrence of work accidents and occupational diseases. The law provides that the insured persons should have the right to timely, swift and best possible medical care. This results in the provision of first-aid benefits, the development of special treatment methods such as cooperation with doctors specially trained and qualified to deal with accident injuries and selected specialist hospitals, the creation of injury clinics and specialist units with departments specifically for serious injuries such as paraplegia, burns, brain damage and chronic pain, the guidance and monitoring of the recovery process by administrative means and the use of professional carers to look after the injured persons, including sick bed visits. In each individual case, the accident insurers are obliged to exercise their judgement in determining the nature, extent and implementation of medical treatment and rehabilitation, as well as the facilities to provide these services. Medical treatment comprises medical practitioners' care, dental care including the provision of false teeth, provision of medicines, bandages and medical aids, home nursing, treatment in hospitals and rehabilitation clinics as well as medical rehabilitation including stress tests and work therapy.

4.5. Following medical rehabilitation, benefits are provided to assist with work rehabilitation. These comprise benefits for the preservation and attainment of a job including benefits to assist with starting work, preparation for employment including the basic training required as a result of damage to health, job induction and training programmes including the training certificates required to take up these benefits, assistance with suitable school education including preparation and development of mental and physical capabilities for commencing compulsory education. Employment assistance benefits also include subsidies for employers if necessary, for example, for permanent reestablishment of employment, a trial period of employment and "on the job" training or retraining. Benefits to aid employment rehabilitation should be provided for the period that is prescribed or customary for obtaining the type of work sought after.

4.6. Benefits for social rehabilitation and miscellaneous additional benefits are also available. These include, inter alia, motor vehicle benefit, housing benefit, care and advice from the social services, housekeeping benefit, reimbursement of travel costs and sport precribed by doctors for rehabilitation purposes and taking place in medically supervised groups.

In cases where nursing care is required as a result of an accident, nursing benefit is paid or a nurse or therapist is provided.

During the course of treatment and employment rehabilitation, injured persons benefit or transitional benefit is paid. Payment of injured persons benefit is dependent on inability to work. Injured persons benefit amounts for $80 \%$ of the regularly earned income. A similar situation applies to the marginally lower transitional benefit during the period of employment rehabilitation. 
4.7. Insured persons who, as a result of an accident, are still suffering a reduction of their earning capacity of at least $20 \%, 26$ weeks after the accident, are entitled to a pension. A full pension amounting to two-thirds of the annual earned income is paid where there is complete loss of earning capacity. A reduced pension is paid when there is a reduction of earning capacity. The pension is increased by $10 \%$ for seriously injured persons.

Accident pensions and nursing benefits are inflation-adjusted every year. The pensions are life-long and continue to be paid after the recipients have retired from active employment.

Unlike private accident insurance, the financial benefits (loss of earnings benefits and pensions) are not contributions-related but are based on the annual earned income of the injured or deceased person, except where special scales are applied (e.g. accident insurance for school children). Dependants are entitled to death benefits, reimbursement of transportation costs, dependants' pensions and financial assistance.

4.8. There can be competition between the benefits of private and statutory accident insurance. The benefits from both types of insurance can be accumulated, for instance a person covered by statutory accident insurance can have taken out private accident insurance providing a daily allowance on a non-indemnity basis. This daily allowance may be received in addition to the medical treatment provided under the social insurance scheme. The benefits can be cumulative if the private insurer has agreed to a non-indemnity based benefit in accordance with the particular requirements of the insured person. In this event, for example, a widow can receive a death benefit from the private accident insurance and a dependant's pension from the statutory accident insurance.

4.9. Summary: Although based on the principle of indemnity, the range of benefits of statutory accident insurance, in fact, goes much further than this, being characterised by the idea of social welfare. It is similar to statutory health and statutory retirement pension insurance in terms of the ranges of benefits offered and, therefore, has the status of a separate social insurance system.

The range of benefits of private accident insurance on the other hand, is based on the sums insured agreed in the policy. In private accident insurance, the extent of the benefits received is dependent on the amount of premium paid. This relationship does not exist in statutory accident insurance.

\section{Financing, contribution and premium systems}

5.1. Private insurance is funded by its premium income in accordance with the risk equalization principle. Premiums are based on risk and contractually agreed in line with the principle of individual risk equalization. The insurance incorporates premium refunds, excesses, maximum benefit limits and conditions (e.g. notification of previous losses) that can lead to prenmium loading and exclusion of benefits.

5.2. Statutory accident insurance eases the financial burden on undertakings by assuming their liability towards insured persons in respect to working accident. It is therefore logical that the accident insurance contributions should be paid by the employers alone. The cost of statutory accident insurance for school children, students and children in kindergarten, as well as quasi-accident insurance claims, are met by the public sector budgets of the regional corporations. 
5.3. Work accident insurance can be financed either by capitalization or by assessmentism ("pay as you go"). The statutory accident insurance institutions started using the capitalization method over 100 year ago. Very early on they changed over to assessmentism. The retrospective assessment of actual requirement means that the actual expenditure of the statutory accident insurance institutions is totalled at the end of the financial year and passed on to those undertakings liable for contributions that year using a predetermined system of apportionment. This assessment system does not take into account future financial obligations of the current members of the statutory accident insurance institutions. For instance the financial consequences of pensions and other benefits relating to serious injuries can last for years or decades. Although this method "pushes" the financial burden forward into the future, assessmentism has proved to be effective: an assessmentism system in respect to the capital value of benefits would lead to the creation of enormous capital sums that would take necessary investment capital away from undertakings and be subject to currency risks. The proven solvency of statutory accident insurance has endured for decades, through world wars and various economic situations, and demonstrates the stability of assessmentism where there is a sufficiently large number at risk. However, problems can arise in some areas where new European regulations allow companies to escape their obligations in respect of the "solidarity" underlying a statutory accident insurance institution by moving their head office abroad.

5.4. An element of capitalization arises in so far as there is a requirement to build up provisions as reserve funds. This reserve should secure the insurance providers' ability to pay benefits during periods of reduced contribution levels (i.e. in unfavourable economic situations) and help stabilize the rate of contribution payable.

5.5. Every financing method has advantages and disadvantages. Criticisms of the retrospective assessment of current requirements include, inter alia, that:

- a part of the retrsopectively assessed amounts turns out to be uncollectable,

- due to membership changes, drawings on the fund and the reserve do not benefit the same members that have built up the funds,

- a reduction of income due to a shrinking insurance portfolio results in sharp contribution increases for the remaining members.

These arguments, and in particular the final one, are significant as sufficient sharing of risk is a basic requirement for all forms of insurance. In Germany, this problem has been answered by the introduction of a finance equalization system encompassing all statutory accident insurance institutions that can credit or debit each statutory accident insurance institution. This equalization method is devised to function as a reinsurance for the statutory accident insurance institutions and prevent the system from becoming insolvent.

5.6. Contributions to the statutory accident insurance are related both to income and to risk. The risk is reevaluated once every five years on the basis of actual incurred costs of accidents.

The use of the financing system for the purpose of loss prevention is particularly advantageous. On one hand this results from adjustments to the risk tariffs across the board in accordance with changes (positive or negative) that have taken place in the accident patterns, and on the other hand by using bonus/malus regulations relating to individual companies. To enable a rapid adjustment of risk classes to the more recent accident development, the costs of accidents that occurred further back in time ("historical costs") are not 
taken into account. The assessment of contributions according to risk categories results in there being over 600 tariff groups if all statutory accident insurance institutions in Germany are taken together.

When the bonus/malus system, care is taken to stay within certain limits so as not to endanger the insurance principle. The insurance principle demands that cover and contribution payable are not directly dependent on the size of the claim to be paid.

It has proven to be advantageous if the risk tariff is independently determined by the employers and employees (with the approval of the supervising state authority) as this significantly increases its acceptability to the undertakings concerned.

5.7. In contrast to foreign solutions, German statutory accident insurance is not solely limited to the provision of compensation. It strives for economic efficiency in its compensation system by employing all suitable means of prevention and rehabilitation. The catalogue of measures taken is a sizeable one: the introduction of accident prevention regulations, supervision and advice to companies concerning work safety, checking work methods and materials used in the production process for work safety, work-related medical precautions, information, training and technical/scientific research. Every year, for example, about 350,000 persons receive training in the maintenance of health and safety at work standard from the statutory accident insurance institutions. The purpose of all preventive measures is to provide the undertaking and its employees at all levels with instructions for acting in a safety conscious manner.

A practical approach to the creation of focused measures that will result in minimising costs can be derived from current sector-specific accident and occupational disease statistics derived from the direct responsibility for prevention, rehabilitation and compensation. This process is supported by the active participation of experienced representatives of the employers and the insured persons in accident prevention committees and other bodies of the statutory accident insurance institutions.

It is debatable whether private insurance companies would be able to match this level of accident prevention work. They lack the authority to standardize accident prevention regulations that effectively have the force of law. The private insurance companies are not organized by trade sectors, whereas it is precisely this sectoral organization of the statutory accident insurance institutions and their resultant specialist experience of the production facilities and work processes of the various sectors that make their accident prevention regulations particularly effective.

The fact cannot be overlooked that policy conditions relating to risk prevention, excesses no claims discounts, and premium refunds certainly do contribute to loss prevention. However, a further effect of these measures is also that the definition of perils for insurance purposes can lead to the misuse of the cover granted. A major problem for the implementation of improvements in prevention measures could arise through competition as, on the one hand general prevention measures entail considerable expense, whilst on the other hand benefiting more or less all companies and therefore other insurers as well. The biggest impediment to achieving a level of accident prevention comparable to that of the statutory accident insurance would be the private insurers' lack of influence over the conduct of those they were insuring. In this respect, the statutory accident insurance providers possess the necessary legal and practical instruments. 
In the final analysis, the desired synergy between compensation, rehabilitation and prevention is only achievable within an insurance monopoly, when industrial accident insurance not only has the duty to provide equitable compensation in individual cases but also to make use of its comprehensive experience to combat the risk of industrial accident and occupational disease.

\section{Insurance providers}

The insurance providers for commercial companies and agriculture are public sector corporations with self-governing rights by the employers and employees. They are subject to State supervision.

The legal constitution of private insurance undertakings takes many forms. These range from joint stock companies to mutuals, small societies as defined in para. 53 of the Insurance Supervision Law, public sector insurance undertakings and limited liability companies. The possibilities of influence available to those insured vary considerably.

The fundamental organization of mutual insurance societies and the statutory accident insurance institutions is based on co-operative self-help.

There is no competition between statutory accident insurance providers. Competition between the insurance providers for a particular sector would only be justified if the individual insurers did not carry out any sector-specific prevention work.

Competition makes little sense, where for constitutional and social reasons the law prescribes the same benefits, the providers work for the public good, i.e. not for profit, and, by using their administrative and organizational powers have been able (over recent decades) to contribute to a continual reduction of the burden of contributions payable by companies for statutory accident insurance.

The statutory accident insurance providers are explicitly obliged by law to observe the principles of efficiency and economy. At least in these two aspects there is proximity to private accident insurance. As compliance with these principles is subject to legal jurisdiction, some operating restrictions certainly arise here in comparison to the private accident insurers.

\section{Comparison of public versus private systems}

7.1. Compulsory industrial accident insurance has been successful due to its organizational basis in the public sector, the combination of the duties of prevention, rehabilitation and compensation into one area of responsibility, the guidance by the participating employers and employees and the inclusion of loss prevention incentives in the system of financing. The costs have decreased from DM 1.51 per DM 100 earnings in 1960 to DM 1.35 per DM 100 earnings in 1989. In the past few years, the average contribution has increased to DM 1.46/DM 100 (1995) due the effects of reunification.

7.2. The work environment represents a discrete area of risk which can be influenced particularly effectively by financial and loss prevention measures via the interface with the firm and the responsibility of employers to protect health and safety in the workplace. Unlike general illnesses and natural deterioration - the areas of risk for health insurance and retirement pension insurance - the causes of work accidents and occupational diseases arise out of the production processes and organization of the companies themselves. Making firms responsible for accidents and occupational diseases from the humanitarian, legal, social and 
financial points of view is thus both the expression and logical consequence of a social market economy. As the work environment is extremely heterogeneous, it would seem obvious to develop and implement the same prevention strategies for comparable work areas where the risk structures are similar, i.e. in clearly definable economic risk groups. This would then result in synergy effects for the whole economy.

7.3. It is hardly conceivable that private accident insurance could provide the same level of benefits as the statutory accident insurance for an average contribution rate of DM 1.46 per DM 100 earnings. For example the public sector accident insurance does not incur

- acquisition costs, marketing commission

- distribution of profits

- market levels of salary and benefits for employees, as the public sector accident insurance providers are subject to public sector regulations, where the principles of efficiency and economy apply and their responsibilities are defined by law.

This can also be clearly seen in a comparison with the premiums of the voluntary foreign accident insurance (available on request per para. 762 Reichsversicherungsordnung / para. 140 of the "Sozialgesetzbuch VII"), which is financed on a capitalization basis, with an albeit small group of insured persons. The overall administration costs of the accident insurance institutions (including costs relating to land, buildings and moveable assets) are under $10 \%$ of the total assessed costs (1995).

7.4. The meaning of solidarity today may be considerably different to what it was at the dawn of the industrial age. The mutuality that finds expression in the solidarity of a mutual liability association continues in particular to be reflected in prevention measures and the common interest therein, and also in mutual benefits. The change from a manufacturing society to a services society has shifted the emphasis of solidarity.

7.5. The management of public sector accident insurance by a partnership between employers and employees, that also extends to the area of operational experience, guarantees an optimum allocation of resources, productivity, business management and efficiency. Here the principles of business management and economy must always be observed.

7.6. Compulsory industrial accident insurance leads to comparable and non-competitive contribution levels for the competing firms within a particular sector.

7.7. Statutory accident insurance releases employers from their liability to employees injured in industrial accidents and thus fosters positive industrial relations in the workplace, which should be a legislative aim. This also applies to the relationship between work colleagues, as accidents caused by work colleagues are also covered by the system.

7.8. The principal reasons that were put forward 110 years ago against private insurance cover for the risk of industrial accident were:

- concern about the partially speculative approach of the insurance industry at that time and

- the assumption that at that time the insurance industry was incapable of a priori assessment of the risks.

These reason are certainly no longer applicable today, in view of the functioning regulatory system that governs the private sector insurance industry and the availability of actuarial experience and techniques. It would be possible to be critical of the fact that the liability of insurance undertakings is governed by the insurance policies and the payment of premiums. 
Given that over 22,000 undertakings become insolvent in Germany every year, it can be supposed that the employees will still have an interest in the security of providers in the event of work accidents and occupational diseases. The dramatic cost development of insolvency guarantee insurance from 1974 to the present day shows that employees have a need for security independent of the legal and financial position of the undertaking.

7.9. A dual insurance regime - as is for example being discussed throughout the world for health and retirement pension insurance systems - namely the provision by social insurance of an inflation related minimum level of cover and additional or individual cover from private insurance, is hard to imagine in the context of industrial accident insurance. This is because the basic structure of industrial accident insurance is directed towards release from liability and to loss compensation and it is not clear how the levels of cover could be split up. 7.10. Whenever there is social policy discussion about the privatization of social insurance risks, claims are made by the private insurance sector that in social insurance too, the contributions levied should be commensurate with the riek, because in statutory insurance they are based on earnings ranges. This argument does not carry weight in the area of industrial accident insurance, because here differentiated risk related contributions are assessed and levied according to the sector involved. These sectors must not fall below a certain minimum size so as to safeguard the principle of solidarity equalization and therefore ensure that contributions remain within reasonable limits.

7.11. The freedom to effect cover is fundamental to private accident insurance and must be seen in a favourable light. It makes more individualised solutions possible and when settling claims, enables the actual extent of health impairment to be investigated. A closer connection between the insured person and his insurance cover could also arise from an individual policy and the circumstances surrounding its inception. Public sector accident insurance is necessarily more formalized. This already becomes clear when comparing the number of regulations: 27 regulations in the Insurance Policy Law and the General Accident Insurance Conditions as compared with 220 regulations in the "Sozialgesetzbuch VII". The legal formulation of many conditions encourages claims consciousness as well as occasional and unjustified dissatisfaction on the part of the insured persons.

7.12. Although they are undefined legal concepts, the maxims of efficiency and economy can, in fact, be implemented by statutory insurance providers in a practical way. In comparison to private insurance undertakings, the requirements of official enquiries, strict rules concerning social data protection and benefit entitlements that are subjectively defined in the public sector have the effect of partially increasing the costs of administration. On the other hand, a large accident insurance institution has administrative costs of $6 \%$; it is questionable whether private accident insurance could achieve this.

7.13. "Private versus Public industrial accident insurance" would certainly become a practical political issue if the current public sector systems of health and retirement pension insurance were to be privatized, as industrial accident insurance being a separate system within the German social insurance system would have to guarantee a range of benefits in line with the comparable risks of illness and old age. A price war, as could for example be observed during the liberalization of the insurance market, would not accord with social political thinking. Privatization is currently an overrated fashion term. Privatization reaches its limits in areas where the State must prevent competition or restrict the permissible number of competitors. Competition creates pressure to make cheaper offers. This inevitably has a negative effect on price, quality or time. 
7.14. A particular aspect arises out of the compensation for occupational diseases by private accident insurers. Work-related cancers that have latency periods lasting decades, during which time the sufferer worked for various employers, must lead to problems in compensation, as the often long latency periods between exposure and occurence of the loss lead to uncertainties when determining which insurer is liable. There are positive connections between the acknowledgement of occupational diseases by the authorities and the targeted prevention measures initiated by the accident insurance providers that do not readily adapt to the sphere of interests of the private insurers. Private accident insurers would have to take out reinsurance or enter into a loss sharing agreement in order to cover occupational disease.

7.15. It is of primary importance that statutory accident insurance aims to prevent work accidents, occupational illnesses and work-related health dangers, thereby protecting the health of the working population, a matter of considerable significance for the common good. The preservation and restoration of the ability to work through the rehabilitation measures provided by the statutory accident insurance institutions is also of immense economic importance to society's wellbeing, as the securing of a reasonable standard of living for the population as a whole is fundamentally determined by the productivity of the workforce. Out of 1,000 injured employees, 974 are rehabilitated and reintegrated in the job market by statutory accident insurance in such a manner as to obviate the need for compensation. 24 receive temporary pensions. In the short term prevention measures are not financially worthwhile. If private insurers were to invest in preventions measures, and particularly general prevention, this would be hard to justify in business terms when an insured company switches to another insurer. If the pursuit of an active health-conscious environment in the workplace were to be abandoned, this would result in health claims being unloaded onto the social systems, above all onto health insurance and retirement pension insurance. Thus from the point of view of avoiding the costs to business and society of work accidents and occupational diseases, and from the savings that can be achieved, the administration of the functions of prevention, rehabilitation and compensation of work accidents and occupational illnesses by self-governing public sector accident insurance institutions continues to be justified now as in the past. 